\section{NEW RADIO-OPAQUE HYDROPHILIC POLYMER}

Smartseal, the creator of endodontic systems, has launched its new radio-opaque smartpoints. The fully radio-opaque hydrophilic polymer, called propoint, has been developed following feedback from practitioners who said they found smartpoints easier and quicker to use but requested the point be more radioopaque so as to be more consistent with other products.

Reader response number 58

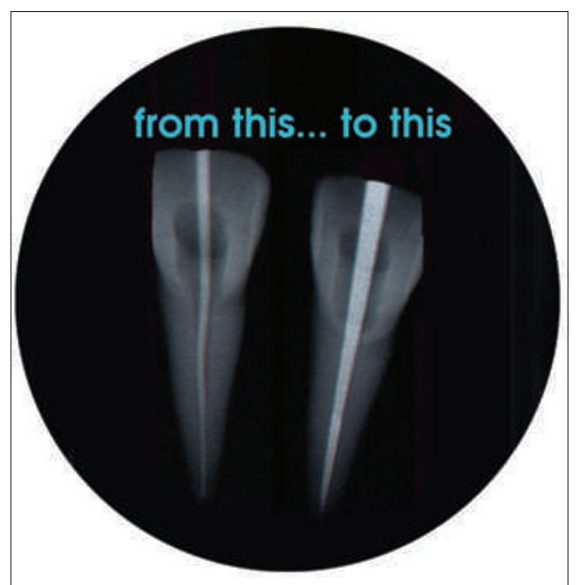

\title{
INTERPROXIMAL REDUCTION SYSTEM
}

The OrthoSpace Interproximal Reduction System makes creating the required spaces for this type of treatment easy and efficient. OrthoSpace is a thin flexible interproximal tool, which facilitates the re-contouring of enamel and will reduce the need for many types of dental materials.

It also enables the often necessary reduction of the interproximal tooth structure, correcting the inadequate space caused by an insufficient arch length. The kit comprises one handpiece EVA system, one extractor, one pack of files and two sets of measuring gauges. Reader response number 59

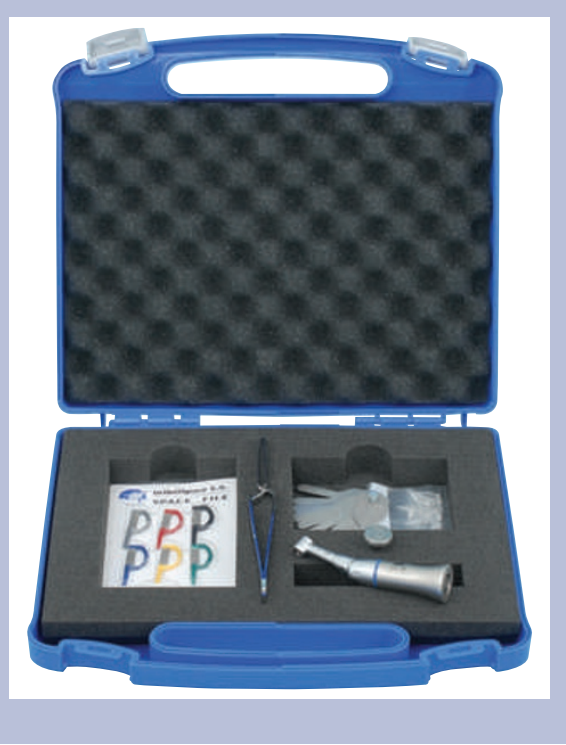

\section{RECEIVE EXPERT ADVICE AND GUIDANCE}

Throughout its five key elements, the Clearstep system presents general dental practitioners with an array of innovative devices including pre-alignment, using the patented CODA to effect expansion in both the upper and the lower arches, and space closure using the

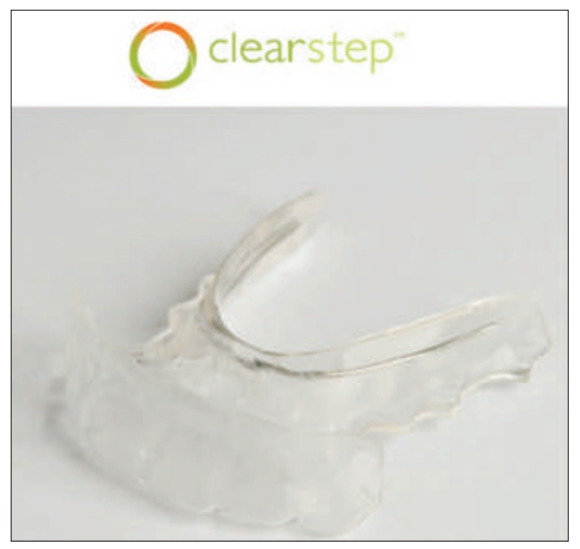

Clearstep Closing Screw, which incorporates a clear polymer positioner and the best screw mechanics taken from traditional orthodontics.

Sets of clear, medical grade polymer positioners enable incremental and accurate movement while you can achieve great results with the Buccal Segment Settling Appliance, elastic mechanics (for GDPs with experience of this method) and the FORD appliance.

You can offer jaw correction for child patients, and effect bodily movement, derotation and much more. The Clearstep System ensures that GDPs receive expert advice and guidance and are also supported by a range of services including pre-activation and pre-adjustment of appliances.

Reader response number 60 